\title{
Visibilidad gay y espacio público en la capital de Aguascalientes: romper para entrar o entrar para romper
}

\author{
Juan de la Cruz Bobadilla Domínguez
}

\begin{abstract}
El artículo habla de la visibilidad que articulan sujetos varones universitarios de identidad gay en la capital del estado de Aguascalientes desde una aproximación estratégica escindida en los procesos de construcción de la identidad y la masculinidad, confrontada con el discurso y la práctica homofóbicos. Se enfatiza la importancia de la inclusión social como principio para la legitimación de las ciudades modernas y democráticas, fundamentadas en la diversidad. El tema central es desentrañar los elementos que vinculan el espacio público y la visibilidad gay en Aguascalientes. El planteamiento versa sobre las estrategias y acciones que, mediante negociaciones y acuerdos, ejercen los sujetos como parte de sus interacciones sociales en la apropiación de espacios para la visibilidad gay.
\end{abstract}

PALABRAS CLAVE: gay, identidad, visibilidad, masculinidad, homofobia, espacio público, negociación social, estrategia

\section{Gay Visibility and Public Space in the City of Aguascalientes: Break to Access or Access to Break}

The article describes the visibility process of college gay males in the city of Aguascalientes from a strategic approach of the masculinity and identity construction processes which confront the homophobic discourse and practices. This issue highlights the importance of social inclusion to legitimize modern and democratic cities founded on social diversity. The main issue is an approach to identify the elements connecting the public space with gay visibility in Aguascalientes, through interacting testimonies and personal insights of some key characters who were informants of this research. This article sets how gay males integrate negotiation and mediation strategies and actions as a part of their social interactions to enhance the appropriation of social spaces providing gay visibility.

KEYWORDS: gay, identity, visibility, masculinity, homophobia, public space, social negotiation, strategy

Juan de la Cruz Bobadilla Domínguez: Universidad Autónoma de Aguascalientes, Aguascalientes, México jubodo2001@yahoo.com.mx 


\section{INTRODUCCIÓN}

A un cuando permea cierto escepticismo entre quienes apuestan por la persistencia de la exclusión, la fragmentación social y la pérdida de identidad, las sociedades urbanas del siglo XxI han generado también una expectativa positiva y benigna que sugiere la existencia de mayores posibilidades para la extensión de la comunicación y los procesos interculturales característicos de la globalización. Este escenario trae consigo una sociedad urbana erigida en la autonomía individual, inmersa en la diversidad cultural y testigo de participación y libertad ciudadanas. Dado que las ciudades son constituidas como el entorno social y político para la reafirmación de las identidades locales y regionales, y con éstas el sentimiento de pertenencia y reivindicación frente al estereotipo ajeno, el espacio de interacción que se debate entre éstas y las nacionales y globales está circundado por una homologación de símbolos, hábitos de consumo e infraestructuras culturales de origen e inserción transnacional (Camacho, 2009: 28-29). La diversidad de las ciudades se encuentra matizada por los procesos migratorios y por la migración interurbana hacia el interior de los países. Pluralidad, multietnicidad y heterogeneidad son las nuevas emergencias que demandan una gestión local tendiente no sólo a minar las tensiones interculturales, sino a organizar y disponer del espacio público de manera que dirija la convivencia de una gama de variantes de grupos sociales. Ante este escenario, las políticas públicas habrán de diseñarse en función de esa diversidad social para responder a las múltiples demandas de sociedades cada vez más complejas.

El tema de la segregación en las ciudades mexicanas ha cobrado relevancia debido a que la transición de las ciudades pasó de una traza urbana en la que el espacio era compartido sin distinciones - aun cuando las sociedades mexicanas se han caracterizado por su desigualdad - a la limitación de espacios que está propiciando una alta y significativa segregación (Camacho, 2009: 30-33). Ante este fenómeno, la investigación que refiere el presente artículo responde a la necesidad de hacer oír la voz de los actores sociales que han vivido la compleja paradoja que implica la inserción social a partir de una adscripción identitaria considerada "transgresora". Metodológicamente, ha significado acceder a la subjetividad que brinda la experiencia de los individuos y entablar un diálogo entre los supuestos conceptuales que les han permitido constituirse como sujetos y las mediaciones involucradas en sus respectivos procesos de socialización.

\section{AGUASCALIENTES}

La capital de Aguascalientes es una ciudad media, ubicada en el centro de la República Mexicana. Forma parte de uno de los estados más pequeños del país y cuenta con una población cercana a un millón y medio de habitantes. En el contexto nacional, la descentralización de los asentamientos generó un patrón ideal de ciudad planeada en el entorno de la modernidad. Las transformaciones recientes de la ciudad de Aguascalientes se ubican en este marco. Desde los años ochenta del siglo pasado, la mayor tasa de crecimiento demográfico a nivel nacional se concentra en las pequeñas y medianas ciudades del país. Aguascalientes se cataloga en este último rango en cuanto a tamaño poblacional. El ascenso de Aguascalientes como entidad federativa responde de manera ejemplar a un proceso de urbanización y globalización contemporáneo. Las tasas de crecimiento del estado, superiores a las del promedio nacional, lo posicionan como uno de los más competitivos en el sector industrial. Sin embargo, esto obedece a una política económica vinculada al comercio y a la inversión extranjera que ha propiciado que la entidad mantenga un crecimiento relativamente estable y constante en las dos últimas décadas. Este impacto global ha favorecido la formación y consolidación de una base económica 
más diversificada, heterogénea y competitiva, en la medida en que las actividades tradicionales y de producción del sector industrial se han combinado con la modernización de otras de fuerte arraigo local, como el comercio y los servicios.

Uno de los cambios más significativos y trascendentales para el estado de Aguascalientes fue su conversión en un centro productor de manufactura para los mercados nacional e internacional al inicio de la década de 1980. Esto trajo nuevas formas de urbanización y una mayor diversificación del espacio urbano para albergar a una sociedad más heterogénea en todos los sentidos, puesto que el perfil demográfico del estado también evolucionó (Camacho, 2009: 36). La ciudad capital de Aguascalientes encierra a su vez una rica mixtura de orígenes regionales producto de continuas migraciones nacionales - principalmente del Distrito Federal, Guadalajara y Zacatecas - y de otras latitudes - como Japón, Estados Unidos y Latinoamérica-, estas últimas por la introducción de empresas provenientes de esos lugares. El registro demográfico demuestra la relevancia proporcional de la población migrante respecto de la de origen. De forma similar, la concentración de población proveniente del exterior en zonas urbanas específicas del municipio de la capital es emblemática. De modo que los estratos generacionales, las preferencias religiosas, el nivel de escolaridad, el lugar de procedencia y la nacionalidad se sumaron en una compleja amalgama de identidades, prácticas, pensares y saberes que hacen de un estado pequeño y tradicional una entidad de atractivo dinamismo social potencial.

Ante este fenómeno, la expansión urbana del estado entró en un acelerado proceso de segmentación de manera no siempre uniforme ni incluyente, en el que predominó una tendencia acentuada hacia la diferenciación social del espacio. El resultado ha sido el surgimiento de nuevas desigualdades sociales, que se insertan en las existentes y provocan la segregación del espacio urbano. Esto es evidente si se analizan los criterios de organización que imperan al momento de asignar, distribuir y licitar los espacios. Sin embargo, la pluralidad cultural que se origina a partir de la migración tiende puentes para una mayor visibilidad de la otredad, puesto que estos estilos de vida, personalidades y formas de pensar permiten resignificar las nociones de las identidades diversas en el imaginario social, a la vez que contrarrestan la presencia y efectos de la discriminación hacia lo diferente. Conforme la diversidad se ha hecho visible en la ciudad de Aguascalientes, distintos marcos de referencia han visto la posibilidad de verse ampliados y han enriquecido, mediante su socialización, tanto las representaciones como las prácticas sociales y sus significados. La ciudad capital de Aguascalientes aún se encuentra en crecimiento, tanto física como poblacionalmente. El hecho de que conserve las ventajas de una ciudad media no aminora la necesidad de recuperación y ampliación del espacio público, la propagación de nuevas centralidades, la proliferación de la diversidad cultural y la mixtura social para crear las condiciones adecuadas de inserción a los procesos implicados. Lo anterior sin olvidar que las ciudades son un espacio cultural y un modo de ser social, un espacio para la colectividad integrado por sujetos cada vez más autónomos.

\section{ACCESO E INSERCIÓN SOCIAL}

Referirse al Aguascalientes social, pleno del sentido que dinamiza el conjunto de sus discursos y prácticas, invita a trazar un perfil en función del ejercicio ciudadano, de sus percepciones y de su registro. Aguascalientes es el segundo estado en el país, con Jalisco, que aplica la Encuesta Mundial de Valores, instrumento en el que se exploran algunos indicadores que merecen ser revisados dada su importancia al constituir el referente de los sujetos protagonistas de la presente investigación: varones universitarios de identidad gay. Los aguascalentenses conciben a la familia como la institución social más importante. La colocan por encima de la amistad, el trabajo, 
el gobierno, la sociedad, inclusive de la religión, aunque ésta es uno de los aspectos esenciales de su vida. Los preceptos morales derivados de la religión definen la manera de ver la vida del aguascalentense mediante los patrones reguladores acerca de lo "aceptado" y "deseable". Nueve de cada 10 personas en Aguascalientes - por encima de la media nacional- profesan la religión católica y se asumen como religiosas, pero aun cuando los preceptos generales de la doctrina son aceptados no sucede lo mismo en cuanto a la imagen de la institución eclesiástica como proveedora de respuestas ante la vida. Respecto de los problemas sociales, la población no considera que sean competencia de la Iglesia y la hacen a un lado a la hora de actuar, lo que se refleja en el grado de aceptación y uso de métodos anticonceptivos, en la justificación del divorcio y en la tolerancia a la homosexualidad (Bretherton, 2009: 72-73).

Dado que la familia otorga al individuo los primeros referentes identitarios, su estructura enfrenta una apertura ante los retos de la modernidad. ra femenina, el cambio en los roles familiares, la incorporación de la mujer en el ámbito laboral, la pérdida del poder adquisitivo del salario y la adopción de nuevas escalas de valores en las generaciones jóvenes son ejemplos de las transformaciones experimentadas en los hogares aguascalentenses a últimas fechas. Los jóvenes en Aguascalientes tienen una nueva actitud ante su sexualidad y las demandas de la sociedad. El cambio social está modificando el contenido de los valores creados alrededor de figuras como el matrimonio: por ejemplo, la virginidad, el uso de anticonceptivos, el divorcio y el compromiso de la sexualidad. La tendencia a lo moderno de la sociedad aguascalentense queda evidenciada cuando, a pesar de considerarse conservadora debido a su arraigada religiosidad, jerarquiza la responsabilidad, la tolerancia y el respeto por encima de la obediencia y la fe religiosa en su escala de valores. Paralelo a ello se percibe un patrón de relativismo moral según el cual las circunstancias específicas de una situación son las que finalmente abonan el

juicio sobre lo correcto e incorrecto en la vida. Néstor García Canclini refiere en este sentido que a pesar de la irrupción, y a veces imposición, de los discursos de la modernidad en las sociedades tradicionales éstas construyen mecanismos para incorporar, adaptar y fusionar dichas representaciones y significados a sus aconteceres cotidianos, en los que se aprecia una negociación que resguarda a la vez que transforma de manera gradual los contextos sociales (García Canclini, 1989: 36).

Los jóvenes en Aguascalientes registran un cambio de patrones en el ejercicio de la sexualidad, dado que las nuevas generaciones son más permisivas en la práctica de relaciones prematrimoniales. Sin embargo, entre los jóvenes que declaran no haber tenido relaciones sexuales prevalecen los patrones culturales tradicionales sobre las actitudes pragmáticas modernas, al privilegiar la virginidad por encima del temor al Sida y al embarazo. Las relaciones extramatrimoniales son altamente reprobadas por el grueso de la sociedad, lo mismo que el aborto, aun cuando entre la población juvenil universitaria esta actitud se flexibiliza significativamente, igual que el uso de anticonceptivos y las relaciones prematrimoniales. Esto refleja una transición en los sistemas de valoración de los jóvenes aguascalentenses. En cuanto a la tolerancia, no se presentan rasgos evidentes de racismo, pero se hace patente el regionalismo, al anteponerse las prioridades locales en el acceso al trabajo. En términos generales, los grupos menos tolerados son los drogadictos y los alcohólicos, seguidos por las personas con antecedentes penales, los homosexuales, quienes padecen problemas emocionales y, por último, los extranjeros. A decir de Bretherton:

La modernización también manifiesta su impacto al abrir las concepciones hacia maneras de ejercer la sexualidad. La homosexualidad es más tolerada que el aborto, ya que sólo la mitad de las personas en Aguascalientes la reprueba de manera total, en tanto que la otra mitad la justificaría de manera relativa. Los jóvenes y la clase media son los sectores más tolerantes (Bretherton, 2009: 63). 
En materia de problemas sociales de la juventud, Aguascalientes presenta índices significativos de delincuencia, drogadicción, alcoholismo, pandillerismo y suicidio, hecho que denota el desfase entre las demandas sociales y las ofertas en materia de políticas públicas de recreación, empleo y educación en este sector de la población. Las alternativas se han dirigido a impulsar la afición prefabricada al futbol, la expansión y segmentación de centros comerciales, videojuegos, bares y cafés concepto, y a la proliferación de franquicias transnacionales de comida rápida, dinámicas que han sustituido a las actividades regionales tradicionales. En suma, el reciente proceso histórico-social de Aguascalientes puede entenderse como una superposición de planos tensionados entre lo moderno y un fuerte anclaje tradicional. Sobresale el predominio general en las esferas pública y privada de los rasgos tradicionales. Los jóvenes son quienes están rompiendo el patrón y se hallan en un estadio de repunte franco hacia lo moderno. Indicadores claros son su apertura manifiesta a distintos modos de pensamiento y su tolerancia hacia nuevas formas de convivencia y cambio de roles sociales. La capacidad de coexistencia identitaria para la proyección de una ciudad más plural e incluyente dependerá del margen que guarden los niveles de exclusión territorial, marginación económica, edad, tribu urbana y de la autoexclusión misma (Bretherton, 2009: 80-82).

\section{VISIBILIDAD GAY}

De unos años a la fecha la visibilidad de la diversidad sexual entre la juventud de Aguascalientes se ha elevado, en específico entre varones gay, quienes hacen evidente su orientación sexual, a la vez que ejercen interacciones que permiten sociabilizarla. A edades cada vez más tempranas los jóvenes gays están conscientes de su orientación sexual y la hacen socialmente explícita. Entiéndase por visibilidad gay al conjunto de manifestaciones, expresiones, formas y significados de interacción social que los sujetos de identidad gay deciden esgrimir individual y/o colectivamente como parte integral de su vida. Son prácticas e interrelaciones producto de la expresión consciente o inconsciente de su identidad, tanto para ellos mismos como para su grupo primario, entorno inmediato y/o espacio público. La visibilidad vive con el actor social, le acompaña bajo múltiples formas, códigos, representaciones simbólicas y manifestaciones inherentes a lo verbal y no verbal, a lo real y a lo subjetivo, a lo inmediato y a lo proyectado.

Hablar de la importancia de la visibilidad gay para el ejercicio de la democracia es partir de la idea de que la salida de un "clóset" identitario no da a la calle, sino a otro espacio que es la pauta para la construcción de una ciudadanía. Más allá de los discursos y las instituciones domesticadoras, las prácticas y los espacios se han multiplicado como resultado de la visibilidad que ha adquirido este sector de la población. Como se ha señalado, los elementos que propician el fenómeno de la visibilidad gay en Aguascalientes forman parte del contexto de la realidad social: la emergencia estructural de la diferencia, una aparente permisividad social producto de la pluralidad, una creciente reivindicación del individualismo sexual entre los jóvenes, la sigilosa democratización de las formas sociopolíticas, todo ello negociado desde la representación del poder a través de la globalización, la digitalización y la emancipación de los derechos humanos. Democracia implica diversidad y al situarla en Aguascalientes es imprescindible citar los espacios públicos de acción colectiva. Aunque todavía no es posible enarbolar una política de lo gay en Aguascalientes, la emancipación nacional ha permeado localmente a una incipiente pero gradual presencia de lo gay a nivel informal, formal e incluso institucional, como parte del imaginario social y de la vida del estado. En la vertiente económica se justifica la pertinencia de la visibilidad gay en Aguascalientes por medio del diagnóstico arrojado por el estudio sobre el "mercado rosa" - pink market - efectuado en la capital de 
Aguascalientes en 2005 por el que suscribe, mismo que corroboró la disposición al gasto inmediato por parte del segmento en cuestión, así como la aceptación de que su comportamiento y patrón de consumo están influidos por su orientación sexual. Estos hallazgos dejan ver el atractivo comercial que este nicho de mercado representa para las empresas locales de productos y servicios asociados al ocio y al esparcimiento, al cuidado y al arreglo personal, variables específicamente prospectadas en dicho estudio. El consumo como una vía importante para la visibilidad, dado su cariz de sociabilidad, permite hacer explícitos comportamientos que los sujetos gay hacen extensivos a la sociedad.

En términos de visibilidad, la identidad gay en Aguascalientes se constituye por dos vías de manifestación en función de la clase y la edad: sujetos jóvenes maduros de clase media y media alta, cercanos a modelos hipermasculinos y pseudoburgueses, y sujetos "obvios" - afeminados-, que concentran una parte del segmento estudiantil de los niveles pleados muy jóvenes, estos últimos de clase baja en su mayoría. El sujeto "obvio", como imaginario de resistencia, se articula en avanzada ocupando espacios públicos cada vez más amplios, es decir, visibilizándose no sólo alrededor de sus entornos inmediatos, sino también en espacios disímbolos y emergentes. Empero, los mecanismos normalizadores del poder han configurado un opuesto en el gay políticamente correcto, es decir, el modelo identitario hipermasculino de clase media. Éste se visibiliza discrecionalmente en su entorno inmediato o en los sitios de ambiente gay, pero no en el espacio público como tal. La visibilidad, presuntamente una estrategia social dirigida a reivindicar y resistir en el ejercicio de los derechos, cuya construcción es resultado de la aceptación de una identidad, es además una estrategia de ligue en función de que incrementa las posibilidades de encuentros sexuales o afectivos; complementariamente, es una forma de sociabilidad entre pares, lo que brinda sentido al hecho de que ante el fenómeno de la visibilidad gay las estructuras

rectoras muestren evidentes fisuras que promueven la subversión y la transgresión en grados y modos diversos:

\begin{abstract}
A medida que van haciéndose visibles imágenes más positivas de la vida gay, los jóvenes que comparten esa preferencia tienen menos dificultad para reconocerse y aceptar su propia condición, a la vez de establecer relaciones menos enfrentadas con el entorno, que a su vez ha incorporado estas identidades a las imágenes sociales. En este sentido, la visibilidad que han alcanzado los gays de los noventa ha sido un elemento fundamental para la construcción de esa identidad en términos afirmativos (List, 2005: 197).
\end{abstract}

\section{LOS ESPACIOS GAYS}

El mundo gay en Aguascalientes es un espacio diverso, prolífico y rico en matices, integrado a partir del núcleo del ocio y la diversión. Este mundo puede ser hedonista y frívolo, superficial e inocuo, pero también realista y profundo, inquieto y crítico. Finalmente, las personalidades de los sujetos son reflejo del devenir de su contexto. Los gays en Aguascalientes, además de actores sociales, son consumidores ubicados en todos los niveles de poder adquisitivo, con características distintivas, pero compatibles. Si bien se trata de ámbitos variados, las experiencias de vida que abarcan muchas veces son comunes. Los antecedentes históricos muestran que el "antro", o centro de reunión nocturno, ha sido el lugar de manifestación e integración de la comunidad gay mundial: negocios - antros, bares o discotecas- que han albergado una confluencia generacional que integra estilos, perfiles y mentalidades. Aguascalientes no ha sido la excepción y mediante esta fórmula el segmento se ha hecho presente, casi siempre de manera clandestina o disimulada en todos los ámbitos de la vida local.

Según Sánchez Tafoya (2005: 26), existe una cultura de lo gay en la ciudad capital de Aguascalientes desde los años cincuenta del siglo pasado, época en la que la comunidad homosexual intercambiaba 


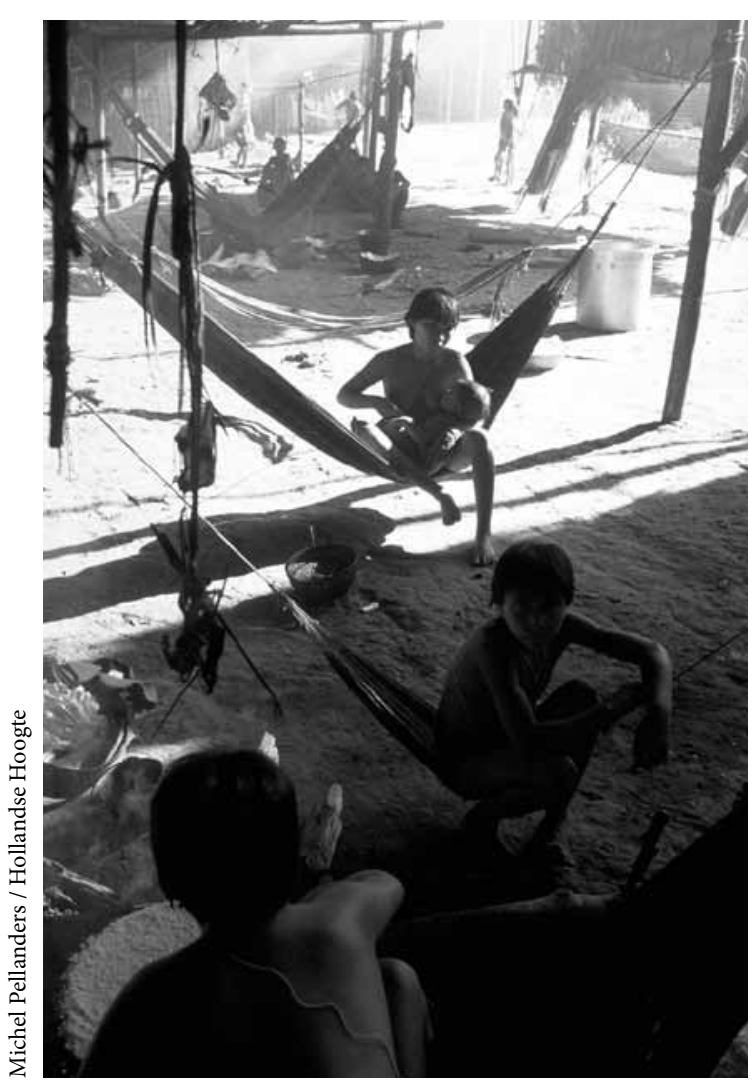

Los indígenas yanomami. Tootobi, Roraima, Brasil, 1996.

opiniones sobre cultura y política a través de actividades sociales, como las tertulias músico-literarias organizadas en lugares como el "Club Monjes", ubicado en la Calle Peña. Durante la década de los sesenta, el "Café Morocco", localizado entonces en el Pasaje Juárez del ahora Centro Histórico, fungió como sitio elitista de socialización de la cultura gay. Durante los años ochenta existió un lugar también en el centro de la ciudad, en la calle Vázquez del Mercado, de nombre "Monjes Lucrecios", donde tenían lugar tertulias entre gays de Aguascalientes. Estos sitios de reunión y convivencia gay operaban de manera clandestina, discreta y/o disfrazada, porque para el resto de la sociedad eran recintos de asistencia pública general.

A inicios de los noventa abrió sus puertas sólo para el público gay de Aguascalientes el lugar de reunión "Mandiles", primero como restaurante y después - hasta aproximadamente 2008- como disco-bar. Este sitio, pionero en la localidad en términos de pérdida de la clandestinidad, marcó la transformación de la visibilidad gay al realizar diversas actividades culturales y otras en beneficio de los derechos de la población gay de la entidad al mismo tiempo que funcionaba como disco-bar. Su mercado, heterogéneo y plural en cuanto a edad y nivel socioeconómico, lo posicionó como un lugar arquetípico que lo convirtió en referente local y nacional en razón de su larga permanencia. Después del surgimiento de "Mandiles" se instalaron otros bares dirigidos al mercado gay de Aguascalientes, aunque problemas legales, de permisos y de administración provocaron su inestabilidad y cierre definitivo. Fue el caso de "El Caporal", "La Jungla" y "Morbo", entre otros.

En 2004 hizo su aparición en el mercado gay de Aguascalientes otro espacio de entretenimiento nocturno llamado "Ryu", bajo el giro de bar-disco, al norte de la ciudad, cerca de la entrada al municipio de Jesús María. Dicho lugar tuvo la peculiaridad de ser mix, es decir, abierto tanto a clientes heterosexuales y gays. Lo novedoso del "Ryu", además de capitalizar la experiencia y el espacio abierto por "Mandiles", fue que explotó la coyuntura que reflejaba la evolución en materia de tolerancia respecto de la diversidad sexual en el estado. Por ejemplo, para apoyar su apertura se lanzó una campaña publicitaria en medios de comunicación masiva que invitaba, como un reto, a los jóvenes aguascalentenses a conocer un sitio "diferente". Debido a cambios de administración, el lugar pasó a llamarse "Liquid" hacia 2006, pero mantuvo su mercado y su enfoque, a la vez que redefinió su concepto para conservar vigencia, motivo de su reciente cambio de ubicación y de nombre.

"Eros Mix Club", ejemplo de las nuevas perspectivas que vislumbraba el mercado gay local, data de junio de 2006 como sitio de diversión nocturna. El hecho de que lograra abrir y segmentar el mercado local, pese a sus limitantes organizacionales, 
constituyó una prueba de su potencial. De vertiente mix, como resultado de la apertura local a nivel juvenil, fue el primer local que previamente posicionado como "antro" juvenil heterosexual direccionara su mercado hacia la población gay de Aguascalientes. Otro lugar de existencia corta fue "Lolitas Gay Club", establecimiento atípico en contraste con los anteriores. "Lolitas" rompió con el prototipo de "antro" gay ubicado en el norte dirigido a un sector de clase media y media alta: se encontraba al suroriente de la ciudad, en un rumbo popular y se concentraba en un sector de nivel medio bajo a bajo. Su particularidad fue que por primera ocasión en Aguascalientes se instalaba un "antro" gay que visibilizaba su enfoque tanto en el nombre como en su marquesina y en su publicidad en bardas. Los sitios referidos hasta este momento a lo mucho habían operado bajo el giro mix y no hacían alusión a su perfil.

Alrededor de 2009, un conjunto de "antros" y bares abrió en el centro de Aguascalientes, específicamente en la avenida Francisco I. Madero. A pesar de la como un circuito, su mercado no era el mismo. "Yermanelas" es un bar-restaurante establecido hace más de una década que está dirigido a un mercado aspiracional de niveles socioeconómicos medio y medio alto, y a pesar de no ser gay o mix cuenta con una significativa clientela gay, por lo que se considera gay friendly - amigable hacia lo gay-. El bar "Fridazz", tradicionalmente heterosexual, cambió de giro para posicionarse como un bar gay de corte popular enfocado a un segmento de edad predominantemente madura y a niveles socioeconómicos medio y medio bajo. Ambos sitios, a pesar de captar un mercado distinto en términos de clase y edad, son sitios recurrentes de precopeo entre los gays. Otro bar es "Caporal", ubicado en una de las principales arterias viales de la ciudad, en la avenida López Mateos, de corte también popular y dirigido sobre todo al segmento de edad madura y con presencia de clientes transgénero. También en el centro de la ciudad, "Xtasis" es un "antro" disco caracterizado por una heterogénea clientela en cuanto a edad y clase social, dentro de la que destacan los jóvenes varones de clase media y mujeres, tanto heterosexuales como lesbianas. Otro "antro" disco de reciente aparición es "District", a un lado de "Yermanelas". En estos “antros" se ofrece a los clientes shows travestis y de strippers, así como concursos y dinámicas promocionales para interactuar con los asistentes.

La presencia de varones heterosexuales en "antros" gay es otro de los elementos que subyacen a la dinámica de apertura e inclusión de estos espacios. En ellos, la masculinidad puede verse resignificada y a la vez confrontada, en la medida en que son espacios de socialización compartidos por jóvenes varones heterosexuales y gays. Pareciera que la manifestación de lo gay en Aguascalientes se concentra sólo en lugares de entretenimiento nocturno, donde ha logrado fincarse. Sin embargo, otros espacios y alternativas se han gestado desde principios de los años noventa del siglo pasado, como la Fundación Aguascalentense de Lucha contra el Sida (Falcons), asociación no gubernamental abocada a brindar apoyo moral y asistencia médica y psicológica a enfermos de viH-Sida durante más de un lustro. La causa de Falcons y otras inquietudes de la población gay fueron retomadas por el Colectivo Ser Gay de Aguascalientes, que ha buscado otorgar una presencia social, política y cultural a la población de la diversidad sexual del estado. Un ejemplo es la serie de instancias promovidas en materia de respeto a los derechos humanos de la población de lesbianas, gays, bisexuales, transgéneros, travestis y transexuales (LGBTTT) contra la discriminación, en la lucha contra el viH-Sida y en favor de las víctimas de dicha pandemia. Además de este Colectivo, existen en Aguascalientes otras organizaciones de la sociedad civil que tienen como eje principal tanto la promoción de la tolerancia y la inclusión de la población de la diversidad sexual como la prevención y tratamiento de enfermedades de transmisión sexual. Aguascalientes no cuenta con un movimiento cohesionado y consistente en la materia dadas las precarias condiciones de estas organizaciones y a la carencia de un proyecto integral, que unificado y consensuado permita articularse. 


\section{HOMOFOBIAY CLÓSET}

A pesar de lo anterior, la homofobia se hace evidente en Aguascalientes y se practica mediante la desacreditación de la identidad, de manera que se insulta, se degrada, se discrimina y se excluye de la vida social heteronormada. La sociedad emplea la doble moral del discurso de la tradición frente a la modernidad y esgrime significados contradictorios, logrando que los sujetos gays se sientan presionados a negociar su identidad desde la masculinidad para no transgredir el orden social. Pese a contradecir lo enarbolado al principio del texto acerca de la presencia de una cierta tolerancia social en Aguascalientes, lo anterior significa que los discursos y las prácticas sociales no siempre guardan coherencia y correspondencia entre sí. El papel social que a este respecto juegan las apariencias y su representación social emerge para otorgar lógica a comportamientos que matizan una interpretación que de otra manera carecería de sentido. La escuela, la fábrica y la oficina semejan un gran clóset, a veces flexible, a veces infranqueable y otras transparente. En Aguascalientes, como en otras regiones del país, y en palabras de Mauricio List, no hay clóset de todo el tiempo ni salida de todo el tiempo. En la ciudad capital de Aguascalientes existen contrastes tan radicales como asesinatos y golpizas por odio, asaltos y abusos perpetrados contra la población de la diversidad sexual, que se mezclan con marchas de orgullo, congresos y cursos sobre diversidad sexual, así como con la presencia de "antros" y bares dirigidos al segmento. La lectura de este diagnóstico hace patente que la homofobia debiera ser vista como un problema de salud pública.

El tratamiento que la mayoría de los medios de comunicación, la jerarquía católica, ciertos sectores del gobierno y los grupos de ultraderecha hacen ostensible contra la manifestación de la diversidad sexual en Aguascalientes comparte espacios en la cotidianidad con la visibilidad y la interacción social que la ciudadanía experimenta por fuente directa de los sujetos gay. No obstante, el ámbito empresarial de
Aguascalientes es un oasis en del desierto de la homofobia. Hay espacios como Industrias del Interior (Inisa), la fábrica transnacional de textiles, que hacen explícito dentro de sus políticas laborales el ejercicio de derechos de sujetos sexodiversos que se integran a su planta laboral y les otorgan visibilidad, como en el caso específico de trabajadores que se emplean bajo identidad transgénero. Un contraste significativo en el espacio público de Aguascalientes es el fenómeno catártico de la Feria Nacional de San Marcos, durante la que se hace visible la igualdad de derechos y el acceso a las identidades sexuales diversas, que conforman un conglomerado social que logra mitigar temporalmente, a partir del inicio del periodo ferial, la homofobia y sus manifestaciones. La Feria Nacional de San Marcos es un espacio para la transgresión que permea en la totalidad de la sociedad de Aguascalientes y deja una avanzada en torno a la visibilidad de la diversidad sexual, sin que por ello desaparezcan durante ese lapso los manifiestos sensacionalistas y discriminadores efectuados por la prensa local característicamente homofóbica. Por tanto, la visibilidad de la diversidad sexual en Aguascalientes, a diferencia de lo que ocurre en la ciudad de México y en otras entidades del país, ha pasado por un proceso más lento y sinuoso para consolidarse, en parte por las estructuras predominantes de supremacía católica.

La manifestación de una identidad no heterosexual, conocida como "salir del clóset", es apenas el comienzo de una vasta serie de capítulos que los sujetos gays enfrentarán en la vida cotidiana durante su existencia. Ser, parecer, decir, callar, aparentar, asumir, dar a entender son siempre los ejes de una visibilidad aparente. Aquel cuya condición transgrede el orden heterosexual está a salvo de señalamiento y sentencia mientras no haga visible su condición. Bersani es contundente cuando afirma: "una vez que aceptamos que nos vieran, también aceptamos que nos vigilaran" (Bersani, 1998: 26). Pero la insurrección de los derechos conquistados por la comunidad de la diversidad sexual en el mundo ha sido una batalla igualmente contundente, 
tanto como la visibilidad de la que ha surgido. Salir del clóset no implica necesariamente el ideal de asumir una visibilidad como forma de vida. El clóset, según Sedwick (1990: 42), es un proceso que nunca termina y que está dinámicamente subordinado a las condiciones del entorno que el sujeto experimenta cada día de su vida y que lo obligan a adaptar, negociar, matizar y dosificar la estrategia que decida articular según la ocasión -laboral, académica, social, vecinal, etc. - para decidir si se da o no a conocer.

\section{REFLEXIONES SOBRE LA VISIBILIDAD GAY ENTRE JÓVENES UNIVERSITARIOS}

Hablar de la realidad social que vive Aguascalientes, de la construcción de una visibilidad gay, de su desarrollo y de su caracterización, en suma, de analizarla y problematizarla, prescribe acercarse a los sujetos sociales que viven dicho proceso y que lo matizan en la medida en que el entorno les ha sido adverso o favorable. Existen sujetos que deciden asumir y manifestar dicha visibilidad. Indagar en esta materia significa acercarse a la construcción personal y colectiva de un proceso: se trata de los sentidos que adquieren las formas de representación, los niveles y lugares de la puesta en operación de esa visibilidad. Las reflexiones que se exponen a continuación hablan de los procesos que permiten la visibilidad de la identidad gay en jóvenes varones universitarios de Aguascalientes. La investigación que se está completando al respecto pretende elucidar las formas de visibilidad que accionan los sujetos en las negociaciones sociales que elaboran a partir de la construcción de su identidad, y dentro de ella, el papel ejercido por las concepciones de masculinidad, a la vez que las articuladas para enfrentar la homofobia.

La Universidad Autónoma de Aguascalientes (UAA) ha incorporado un curso de formación humanística, cuyo objetivo es reflexionar acerca de la diversidad sexual y más específicamente sobre la identidad gay. Busca brindar a los estudiantes elementos que permitan su visibilidad, además de la prevención de infecciones de transmisión sexual (ITs) y la conciencia sobre los derechos sexuales de los jóvenes. El grupo de estudiantes que ha participado en las tres ediciones efectuadas hasta el momento, desde enero de 2010, se ha conformado por jóvenes de la UAA y de otras universidades, de carreras y semestres diversos, residentes en distintos municipios y en la capital del estado, de origen rural y urbano, de clase media y media baja, y con un promedio de edad de 21 años. Bajo el nombre de “Gallos LGBTTTIH en acción”, que es también el nombre del curso, alrededor de una treintena de jóvenes universitarios anteriormente censurados y

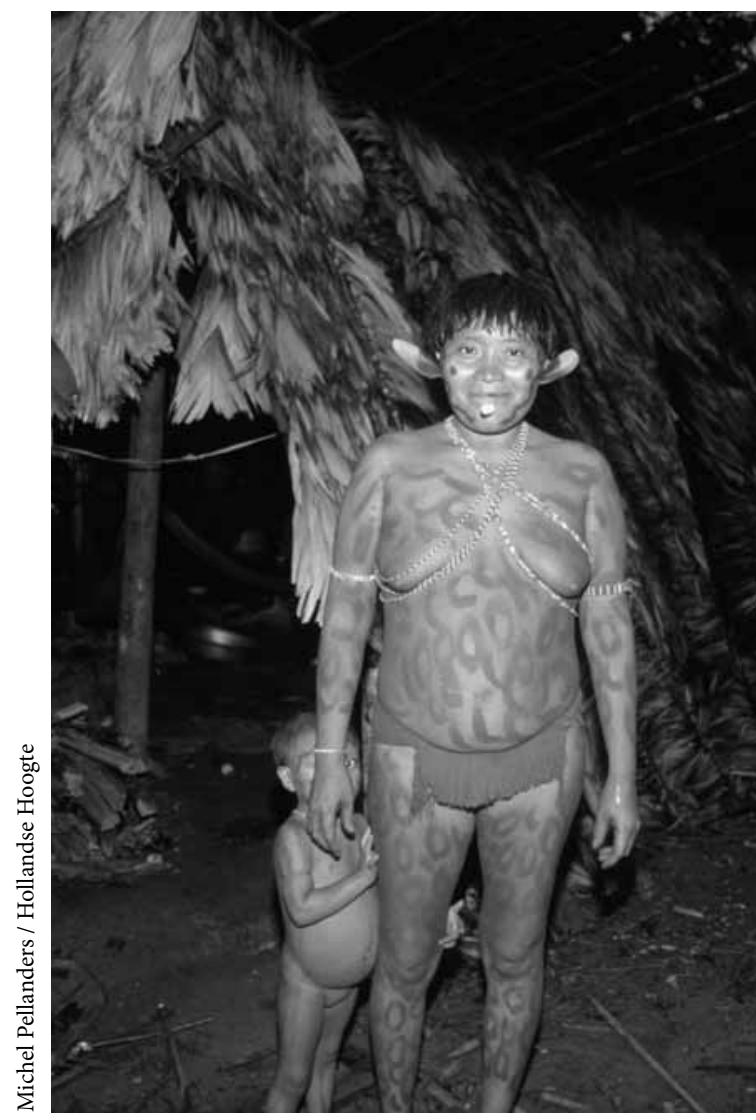

Mujer yanomami, madre, pintada con urucu. Demini, Roraima, Brasil, 1989. 
sin referentes contextuales dentro de la institución se han abierto a una realidad que los hace visibles en el ámbito académico, al tiempo que les allana un camino para su empoderamiento como sujetos mediante la construcción de un "nosotros", a partir del reconocimiento que han logrado. Los jóvenes de este grupo universitario de reflexión son depositarios de una coyuntura que está tendiendo puentes para su aceptación e inclusión en el imaginario de la universidad. De las interacciones producto de su emancipación conformarán el proceso de visibilidad en su universidad y en otros ámbitos de la ciudad, gracias a las actividades que llevan a cabo al interior y exterior de la institución. Desde enero de 2010 se ha establecido una relación de cercanía y seguimiento con las tres generaciones egresadas.

Estos jóvenes componen la muestra de los sujetos de estudio para la presente investigación. El trabajo de campo, que consiste en el método biográfico, arroja registros de las historias de vida de cinco sujetos varones universitarios, seleccionados a partir de la experiencia del grupo de reflexión. A continuación presentamos algunos testimonios en los que destaca que los informantes reconocen su capacidad de agencia para constituirse como sujetos mediados por el contexto, sobre todo por la familia, lo que los conduce a asimilar el papel que indican las estructuras. Esto los induce a la generación y apropiación de discursos discontinuos que a veces resultan contradictorios con el significado que otorgan a la adscripción a la identidad gay — esencialismo $v s$. construccionismo, integracionismo $v s$. separatismo-, por lo que deambulan con un desconocimiento de la noción histórica de la identidad gay y de las ambivalencias consecuentes respecto del significado atribuido al concepto en su imaginario. Es decir, algunos consideran que la orientación sexual no les asigna identidad porque se define sólo en función de su sexualidad o de sus prácticas. Otros manifiestan lo contrario: afirman que en esa diferencia, la de su orientación sexual, radica su esencia como sujetos, su ser, personalidad y estilo de vida. Los jóvenes están conscientes del valor simbólico asignado a los estereotipos construidos socialmente alrededor de la identidad y la sexualidad, y aun cuando no se identifican con ellos, o no del todo, tratan de construirse tomando distancia, pero aceptando su influencia como un referente a veces único para ubicarse a sí mismos e insertarse socialmente. A continuación, un ejemplo de cómo opera dicho proceso en función de los roles sexuales:

Pues obviamente califico eso como algo mucho más positivo, algo más, una riqueza sexual que no pueden tener los heterosexuales porque me imagino que..., o lo veo aburrido, el simple hecho de jugar nada más un rol, de no poder hacer otra cosa, de no poder experimentar algo más. Y en nosotros los gays me gustó más que se pueda ser pasivo y activo, que puedas experimentar las dos cosas y que las dos cosas sean placenteras y que te guste. Para mí eso fue algo positivo, un extra que los heterosexuales no pueden tener por sus... ¿Cómo te diré? Según ellos, no pueden tener sexo por detrás, porque tú y yo sabemos que ellos pueden tener relaciones sexuales con una mujer y que la mujer puede excitar al hombre tocándole la próstata, pero ellos en su vida, me imagino que ningún heterosexual permite que su mujer le haga eso, que le meta el dedo porque ya estarían cayendo en el prejuicio de que "a lo mejor soy gay porque me gusta que me metan el dedo ahí" y por eso mejor, nosotros los gays tenemos ese extra, ese placer extra. A mí sí me gusta que haya roles, o sea, yo que soy "ínter", disfruto los dos y me gustan mucho (Cega, 21 años).

Este testimonio revela cómo los sujetos asumen los estereotipos de la sexualidad y de lo gay como construcciones sociales, a veces ajenas a su propia psique, a su necesidad de identificación, sentido de pertenencia y reconocimiento social. Consideran que su construcción como sujetos es un proceso individual, personal e íntimo, que no debe estar sometido a encajar en moldes socialmente impuestos. Sin embargo, el factor al que confieren importancia en ese sentido es la mediación familiar, vista como legado formativo que les ha enseñado a vivir, a pensar y a valorar tanto su vida como la de los que les rodean. Damos otro ejemplo de la construcción identitaria 
que lucha y desafía estereotipos y que expresa un sentido transgresor a partir de la subversión y la resignificación del orden genérico y la norma heterosexual:

\begin{abstract}
Al principio pensaba que eso era lo que se creía: así nos expresábamos y así tenemos que expresarnos. Dije: "la sociedad nos lo impone". O sea, no sabemos ser hombre ni mujer, pero si nos dicen: "Es que el gay hace esto", entonces yo voy a hacer eso. Y van y jotean y la chingada. Pero luego vi que es más como: “'Soy gay! ¿Y? ¿Puedo jotear? Sí. ¿Puedo ser hombre? Sí. ¿Puedo ser mujer? ¡Más femenino que tu hermana!”. Sí. Como que fue, ahorita lo siento así, una revolución social, podría decirse. Como que nos estamos quitando los estigmas machistas, de que el hombre tiene que ser así. “¡No! Puedo ser mujer, ¡más que tu madre!”. Nomás porque no tengo con qué parir hijos, pero yo siento que es eso, la revolución de todo, tanto de mujeres como de hombres. Joteo porque puedo (Speedy, 21 años).
\end{abstract}

Para el proceso de construcción identitaria, los sujetos toman en cuenta que al sentirse fuera del orden social heteronormativo están en posibilidad de construirse uno muy particular, con su sistema de valores, que sustituya al vigente para el resto de la sociedad. Han resignificado esta circunstancia y la asumen no como una exclusión inherente a su condición, sino como una alternativa de autogestión para con su elección de vida. Puede decirse que el espacio público - entendido como espacio comunitario de convergencia ciudadana y lugar de gestación de una comunidad basado en el reconocimiento mutuo (Treviño y De la Rosa, 2009: 28) — en el municipio de la capital de Aguascalientes es parcialmente amigable con la visibilidad gay, o al menos no representa persecución o amedrentamiento, situación que no comparte, por ejemplo, la población transgénero de la ciudad. En algunos casos y zonas de la ciudad, este espacio funge como refugio ante el acoso y la presión familiar que algunos sujetos viven en casa. Entonces el individuo sale y toma la calle para poder ser él mismo. Es decir, toma la calle como espacio de expresión de valores y propuestas, como integrante de la sociedad civil. La cita en el merendero, ir a un café del Centro Histórico o a pasear por la plaza principal son actividades de sociabilidad que permiten a los sujetos una visibilidad. En cuanto a ésta, podría decirse que los sujetos se encuentran en un momento de transición. Mientras que el contexto social actual es favorecedor en materia de diversidad, visibilidad e inclusión social — la aprobación del matrimonio civil entre personas del mismo sexo en el Distrito Federal y su lógica repercusión al interior del país-, en el polo opuesto, el entorno familiar, predominan aún saberes conservadores y homófobos emanados de la religión católica. Es decir, en el espacio público estos sujetos pueden visibilizarse sin temor a padecer una franca discriminación, y si son objeto de ésta - miradas y comentarios- no suele ser algo relevante para ellos, dado que conocen medianamente las leyes estatales en materia de discriminación, pero dentro de sus hogares algunos todavía permanecen ocultos o semiocultos, y desean mantenerse así, al menos por el momento, según sus historias particulares:

Si alguien me preguntaba si era gay o se me insinuaba o me decía algo así, ponía mis barreras y decía: "No, yo soy heterosexual, me gustan las mujeres", y en mi trabajo hacía comentarios como: "Miren a aquella vieja”. Después me alejé de todo eso. Ya no tiene caso que todavía ande diciendo todo esto, ya empecé a alejarme de comentarios así. Desde ese día dije: "Si alguien me pregunta en buena onda que si soy gay, voy a decir que sí'. Pero nadie me preguntó. Sentía que antes sí me detenía mucho como a expresarme o hablar más, como que sí era un poco difícil estar dentro del clóset por mi mamá. Yo decía: "Si mi mamá supiera podría hablar más de.... Es complicado explicarlo. Siempre me detuve por mi mamá y ya cuando supo, ya no me detenía en muchos aspectos. Como te digo ahorita, si me preguntan que si soy gay, les voy a decir que sí, porque mí mamá ya sabe. A lo mejor fue eso en lo que cambié mentalmente, o sea, de adentro, que si alguien me preguntaba ya no me costaba trabajo decirlo, ya no me conflictuaba eso (Cega, 21 años). 
Los sujetos perciben su visibilidad en sitios públicos como una toma del espacio para la expresión de algunos elementos de la condición gay y exhiben comportamientos de interacción que eran exclusivos de los heterosexuales. Estos elementos abarcan códigos y manifestaciones no verbales de afecto, camaradería y contacto físico primordialmente, que exteriorizan los grupos de amigos y los sujetos con pareja. Saludarse de beso, hablarse en femenino o "jotear" en voz alta, abrazar al compañero e incluso el "faje" en broma son expresiones ejercidas en público por los sujetos. Pero en su imaginario persiste la idea de que en la medida en que masculinizan su imagen y su comportamiento se tornan asequiblemente visibles. Hacen de la masculinidad una estrategia para la visibilidad, lo cual responde a un marcador de sexualidad y género - voz, apariencia - de cierto tipo de sujeto gay, a un tiempo y lugar histórico específicos, y finalmente a la reproducción del orden genérico normativo. Sin embargo, las expresiones de gaycidad guardan un proceso de selección y pasan por un filtro al momento de su puesta en acción en el espacio público. Los sujetos elaboran una clasificación, a manera de código, acerca de los lugares considerados "propicios" y/o "amigables" para exhibir estos comportamientos. Los territorios favorables se encuentran en dos zonas específicas de la ciudad: los alrededores de los "antros" y bares gays y la Plaza Central o de la Exedra, ambas en el Centro Histórico, y las calles anexas. Además, la UAA, el interior de algunos conjuntos cinematográficos y una serie de cafeterías localizadas en el Centro Histórico son los espacios que pueden ser considerados "amigables" en tanto haya de por medio una negociación de parte de los sujetos. El siguiente testimonio ilustra cómo los sujetos articulan conceptualmente la apropiación de dichos espacios como una forma de reivindicación a su condición:

Porque yo sé que en el centro, si a la gente no le parece, ipues se aguanta!, porque hasta cierto punto estamos en una ciudad en donde se supone que debe haber respeto y una forma de respetar es que si a mí me gustan los viejos, pues que me respeten, ¿no? Aparte que la ley, ¡yo no sé de leyes!, pero yo sé que aquí en Aguascalientes protegen, ¿no? No hay discriminación, no debe de haber discriminación. Entonces, por eso lo hago, y también por ganas. Por ganas que tengo de ir haciendo conciencia en la sociedad de que ésta es la realidad, les guste o no les guste, y me gusta hacerlo a mí, no por exhibicionismo, sino porque quiero, esto es personal conmigo, porque quiero que vean, no soy la típica loca que lo hace por exhibición, soy un chavo normal, que va agarrado de su chavo normal, porque somos novios y punto. Y eso me gusta. Me gusta hacerlo por eso. Porque te puedo asegurar que muchos de los que nos ven ahí se preguntan: “¿Ah, cabrón, mira éstos?". No son las dos loquitas, que a lo mejor ante sus ojos de repente van a decir "pinches locos!". Pero no somos las dos locas que se esperan ver agarrados de la mano. Por eso lo hago también (Pantro, 27 años).

Esta acción, asumida por el sujeto como proveedora de conciencia y reivindicación social, si bien guarda ciertas reproducciones de homofobia internalizada en el modo de representación, es finalmente una estrategia de visibilidad individual que coloca en el espacio público una apuesta empoderada y emancipadora de dos sujetos varones gays, bajo el arquetipo de una relación erótico-afectiva cuya carga simbólica desafía la heteronormatividad. Esta estrategia se presenta en un marco contradictorio, porque se mezcla con la aspiración de ajustarse a la normalidad, es decir, a una asimilación a fin de lograr la aceptación e integración del sujeto al orden social. La negociación sobreviene a partir de que el sujeto plantea su integración a cambio de la aceptación de sus prácticas sexuales bajo los términos identitarios que le definen, aunque su parámetro sea el de adecuarse a las estructuras dominantes.

A su vez, el espacio público funge como receptáculo de opciones y posibilidades de encuentro sexual, ligue o simple coqueteo entre los jóvenes que se dedican al sexoservicio, a "chichifear" o simplemente a ligar, concentradas por tradición desde décadas atrás en las calles aledañas a la Plaza Central o a la Exedra. Esta práctica de acceso sencillo, rápido 
y fugaz al contacto entre gays es conocida por la comunidad gay local como la "putivuelta". Sin embargo, los informantes manifiestan prejuicio hacia esta dinámica, principalmente por factores de edad y clase. Este recurso de socialización del sexo responde para ellos a la necesidad de un nicho de mercado de edad madura y/o a un segmento de nivel socioeconómico bajo. Interpretan esta representación pública de lo gay en la cotidianidad como una paráfrasis de la prostitución heterosexual, por lo que los sujetos reproducen su carácter censurable, tanto para el individuo que ofrece como para el que toma, lo que articula elementos del discurso homofóbico. Es pertinente recordar que la sociedad aguascalentense aún conserva preceptos de arraigo moral y religioso que censuran en general este tipo de comportamientos. Aunque los jóvenes procuren romper con los paradigmas del caso, resulta evidente que la preproducción de los discursos hegemónicos continúa interiorizada en muchas de sus concepciones alrededor de la sexualidad. No obstante, es interesante tamente estan dispuestos a explorar la riqueza que la tamente están dispuestos a explorar la riqueza que la diversidad provee. Las evidencias son cada vez más frecuentes y significativas, sin que la censura deje de estar presente. Muestras de visibilidad colectiva, como la realización anual de la Marcha de la Diversidad Sexual, ponen de manifiesto la participación de los sujetos en causas sociales y dejan ver que la diversidad de criterios todavía es amenazante para el orden hegemónico. Esto es parte de las contradicciones inherentes al proceso de transformación que vive la ciudad. Pantro fija su postura en torno a la inclusión social de lo gay desde su propia experiencia:

Sería genial, que como seres humanos que somos y parte de una sociedad, o sea, el respeto nos lo tuviéramos ganado, pero no es así. O sea, la realidad no es así. No le vas a venir a decir a una sociedad mal educada, no les vas a decir: "Deben respetarme porque soy un ser humano como cualquiera de ustedes y bla, bla". No se los puedes venir a decir porque no están educados, en todos los aspectos de educación. Entonces, si no están educados, ¿cómo fregados va

uno así: "Tres heterosexuales pueden entrar con su novia y yo gay puedo entrar con mi novio", ¿no? O sea, no. Te digo, tienes que ser un poco más sutil, no por ellos, ipor ti! Porque no te debes a ellos ni lo tienes que hacer por ellos, lo tienes que hacer por ti, porque no te ganas una falta de respeto que no quieres, pero te manifiestas. Bueno, generalmente es eso (Pantro, 27 años).

La negociación que los sujetos articulan sobreviene cuando se muestran públicamente y formulan quién o quiénes pueden ser receptores y si conocen a su familia. Es decir, surge el papel que juega el círculo social y el grado de sociabilidad del sujeto y la familia, que en una ciudad pequeña en la que los grados de interacción social son próximos - "todo mundo se conoce" - pueden hacer peligrosa la exposición para el individuo. Esta circunstancia es asimilada como transitoria en la medida en que las posibilidades de encuentro, conocimiento y coincidencia o no entre los receptores sociales de su visibilidad y sus familias está fuera de su control y de su conocimiento. El factor del riesgo es esencial en la negociación: el sujeto percibe que la inminente situación de su descubrimiento vendrá tarde o temprano, lo que puede definirse como un outing - forzar la salida del clóset a un sujeto mediante la coacción, el chantaje o la revelación de su identidad-, que es precisamente uno de los elementos que la negociación brinda como proceso de preparación y asimilación. Los sujetos reaccionan y responden estratégicamente para enfrentar el outing: hacen efectiva su salida del clóset, prolongan el proceso, desvían la atención, lo ocultan, lo niegan, etc. La capacidad de agencia del sujeto se verá trastocada siempre que, de origen, su interacción social y negociación con el entorno y el grupo primario estén regidas por la incertidumbre del escrutinio público, que lo obliga a definirse, asumirse y reconocerse en su identidad sexual. La amenaza, el interrogatorio y el rumor serán al unísono o en forma intermitente los artefactos que librarán continuamente una batalla de negociación social entre los sujetos gays y la sociedad heterosexual. Habrá que recordar que: 


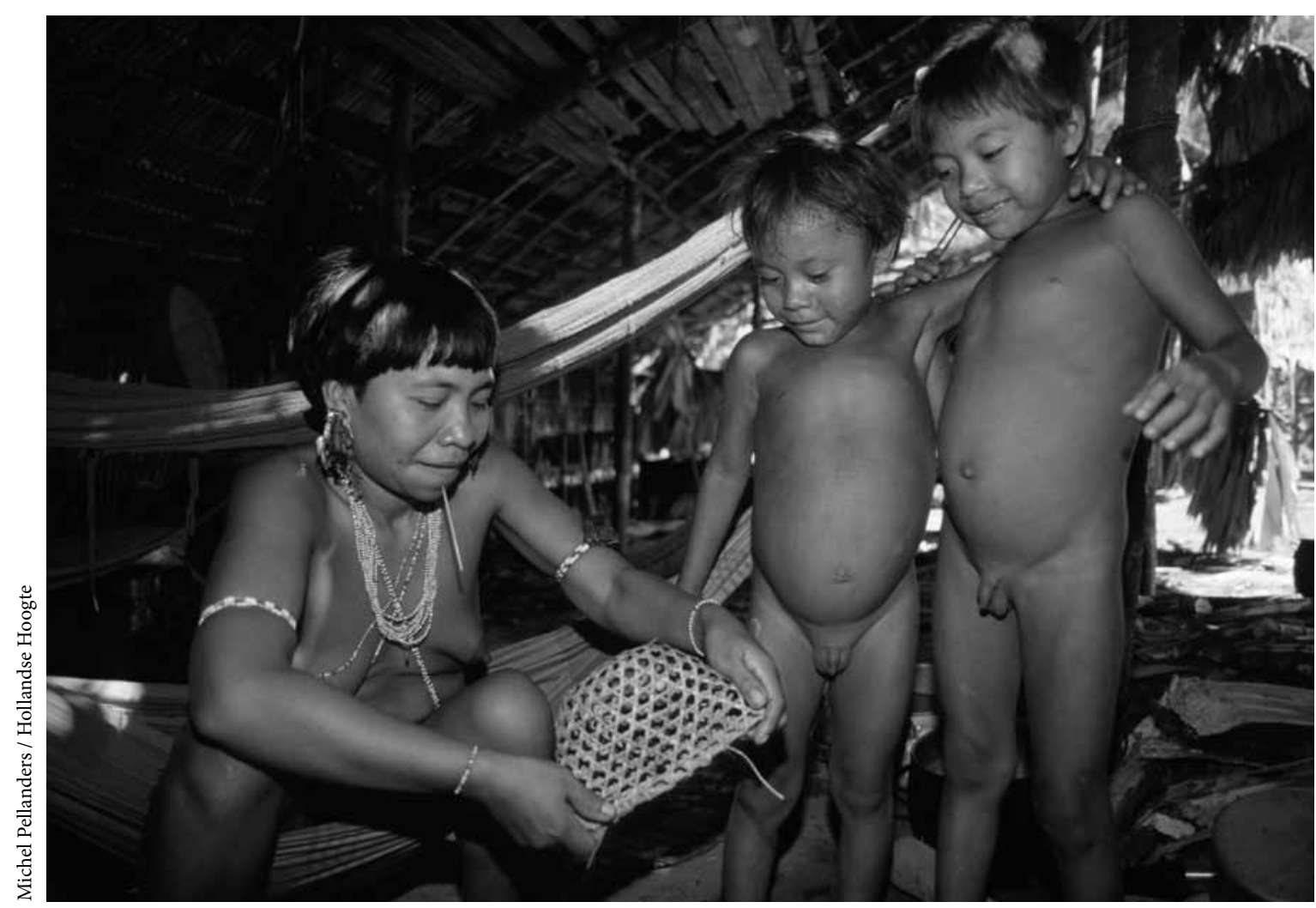

Indígenas yanomami en la maloca. Tootobi, Roraima, Brasil, 1996.

la mayor intolerancia es hacia la visibilidad de lo gay; lo que provoca las reacciones más airadas, violentas y agresivas es la presencia abierta de los gay. No importa tanto que los sujetos tengan una sexualidad diferente a la heterosexual y la ejerzan, lo que más provoca la ira de los intolerantes es su muestra pública, pues ello implica asignarle un sitio dentro del universo sexual (List, 2009: 152).

El Estado que prescribe la "diferencia" y la exclusión del orden social heteronormativo crece con el sujeto gay y lo va formando dentro de un mundo en el que su posición y su nivel de autoestima giran alrededor de la incertidumbre, el miedo y la desconfianza. De ahí que el sujeto gay asuma una condición reforzada de aparente ventaja y superioridad sobre el resto de sus semejantes. A lo largo de su vida ha desarrollado una experiencia cognitiva que le ha brindado supuestos que le son familiares y con los que ha tenido que lidiar desde que se supo y se asumió diferente. Cuenta con la ventaja de conocer los efectos del término "incertidumbre", de manejar estratégicamente sus diatribas y de elucidar sus desatinos, cualidades que lo colocan en una posición en la que pareciera estar más preparado y apto para sobrevivir que el resto, como lo muestra el siguiente testimonio:

No sé cómo decirlo, pero sí te das cuenta o sí sientes dónde puede haber homofobia o qué personas la pueden tener porque..., ¿cómo te diré?, nosotros tenemos como un radar, por decirlo así, para ubicar los chavos gay, asimismo que nos damos cuenta quién puede tolerar o quién no, o de repente quién nos puede agredir, igualmente por el aspecto o por la cara. No sé pero sí nos..., o bueno, yo sí me doy cuenta o sí siento dónde sí puedo y dónde no. No sé cómo explicarlo, pero lo sé (Cega, 21 años). 


\section{CONCLUSIONES}

En la vida de los sujetos pueden leerse las transformaciones sociales. Recuperar los discursos a partir de los imaginarios implica encontrar las contradicciones en cada grupo o sociedad. Debe entenderse que la sexualidad de los sujetos no pasa por un dispositivo racional y que la identidad no emerge sólo de una biografía, dado que registra desplazamientos según la experiencia y el contexto. Ha sido importante elucidar cómo se reconoce el sujeto en su propia historia, con sus trayectorias y sus transiciones. La biografía se torna compleja por las interacciones que permean entre sexo-género, clase, etnia, homofobia interna y externa. Lo vertido aquí refleja la experiencia subjetiva que se construyó con los informantes en conjunto durante los dos años de convivencia y contacto con el grupo referido en el proceso de obtención de información. Estas reflexiones son el principio y la base de la investigación que, una vez concluida, guiarán la discusión para develar el proceso de visibilidad de estos sujetos y las estrategias de socialización emanadas y articuladas en función del mismo.

He pretendido desentrañar los procesos sociales que permiten a los individuos construirse como sujetos. Desde la periferia están convidados a constituirse en actores sociales cuya capacidad de agencia genere estrategias y negociaciones en su ámbito primario, en su entorno inmediato y en el espacio público. Al hacerse visibles, probablemente logren incidir resignificando, revirtiendo y transformando su realidad hacia formas más justas, democráticas e incluyentes de convivencia. En suma, como parte vital de las prácticas performativas que accionan los sujetos gay en sus procesos de interacción, la visibilidad en el espacio público, vista como instrumento de legitimación social de una identidad transgresora, o como toma del espacio para la manifestación y expresión de la misma, representa uno de los eslabones más importantes en la conformación de los imaginarios sociales alrededor de la diversidad sexual y una de las mayores conquistas en el plano de los derechos humanos.

\section{Referencias bibliográficas}

Bauman, Zygmunt, 20 Tiempos líquidos, Tusquets (Colección Ensayo), México.

Bersani, Leo, 1998, Homos, Manantial, Buenos Aires.

Bretherton, Regina, 2009, "Valores y cambio social”, en Silvia Bénard Calva y Olivia Sánchez García (coords.), Vivir juntos en una ciudad en transición. Aguascalientes frente a la diversidad social, Universidad Autónoma de Aguascalientes, Aguascalientes.

Bobadilla Domínguez, Juan de la Cruz, 2006, "Diversidad sexual: reflexiones sobre el mercado gay”, en María Amalia Rubio Rubio (coord.), Rompiendo diques. Hacia una construcción de la equidad de género, Universidad Autónoma de Aguascalientes, México.

, 2010, "Haciéndose visibles... más allá del clóset", en Caja de Arena. Suplemento Cultural Catorcenal, p. 24.

Camacho Sandoval, Fernando, 2009, "Encuentros y desencuentros frente a la globalización”, en Silvia Bénard Calva y Olivia Sánchez García (coords.), Vivir juntos en una ciudad en transición. Aguascalientes frente a la diversidad social, Universidad Autónoma de Aguascalientes, Aguascalientes.

García Canclini, Néstor, 1989, Culturas híbridas, estrategias para entrar y salir de la modernidad, Grijalbo, Consejo Nacional para la Cultura y las Artes, México.

List Reyes, Mauricio, 2005, Jóvenes corazones gays en la ciudad de México, Benemérita Universidad Autónoma de Puebla, México.

— 2009, Hablo por mi diferencia. De la identidad gay al reconocimiento de lo queer, Eón Ediciones, México.

Sánchez Tafoya, Édgar, 2005, "Identidad gay en los varones jóvenes de Aguascalientes", tesis de licenciatura en sociología, Universidad Autónoma de Aguascalientes, Aguascalientes.

Sedwick Kosofsky, Eve, 1990, Epistemología del armario, University of California, Berkeley.

Treviño Carrillo, Ana Helena y José Javier de la Rosa Rodríguez, 2009, Ciudadanía, espacio público y ciudad, Universidad Autónoma de la Ciudad de México, México. 